\title{
A Friendly Bluebird
}

Kenneth Knox, Clair, Sask.

WITH winter fast approaching and most of our summer birds gone, one cannot help but wonder if our special friends will come back to us another year.

The accompanying

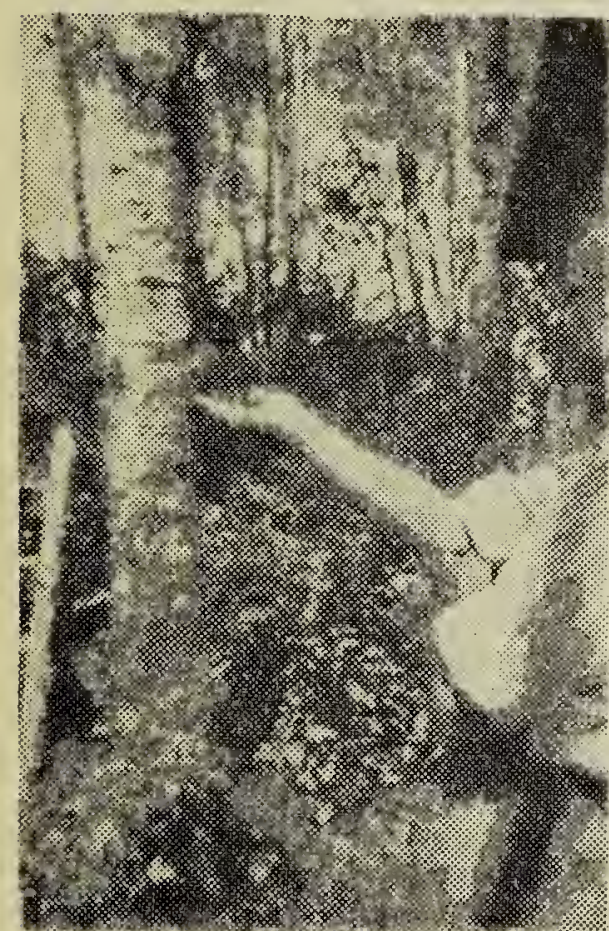
photographs will show what I mean by a special friend, which of course, is a Mountain Bluebird. The y commenced to build their nest on the fifteenth of May, and chose the out-house for their site, which more often than not in past years was occupied by the cheery little House Wren. The fem a le Bluebird in particular became very friendly. On July the second, much to my amazement, she landed on my hand for a moth which I had held out

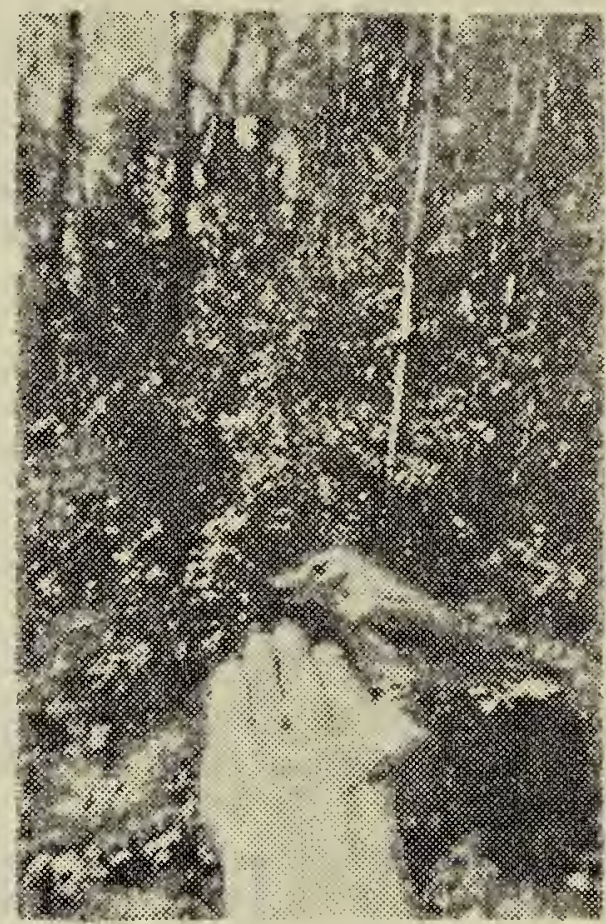
for her. She soon be-

came a friend also to visitors, and would take a moth or even dozens of them held out for her by anyone who had a few minutes to spare. A piece of dry leaf would bring her down if a moth wasn't handy. She would fly with it to a tree, drop the leaf and wait for a better handout.

During the following thirty days there was only one when she missed having moths given to her. On August the first Mr. and Mrs. Bluebird and a family of six left us, the babies having tried their wings four or five days before that. Up until the last the mother still accepted handouts of moths which by this time were getting smaller and smaller but, no doubt, were greatly appreciated.

One may wonder where the supply of moths came from. Well the greatest supply was found in the binder canvases. Nearly every day I would unroll them, kill the moths, leed just a few and keep the rest for later on in the day. I would then roll up the canvases in preparation for another catch the following day. Soon the Bluebird caught on to where I got the moths, and each morning when I would go to the garage to unroll the canvases she would be there too, and would fly down to help herself, should I be too slow in giving some of the moths to her. Moths were also caught under cardboard that I tacked to the walls of the granaries. Two of my friends, who enjoyed feeding the Bluebirds, on two occasions, brought moths from their homes to save the supply here.

I think it is quite a thing to have a pet Bluebird around home, but the time that it landed on my hand when I was a quarter of a mile from home was an occasion that I will not forget very soon. On July 24, while I was watching the breakers turning over the good old sod, the tree stumps and even the worms, I could not help but notice the busy Blackbirds and Bluebirds following the outfit. I found a worm, and there being a few Bluebirds close by, thought I would hola the worm out in my hand to see if our pet was one of them. Sure enough, in less than a minute didn't our friend come and land in my hand for a few seconds, but to my surprise she flew away without the worm. 